\title{
Nursing activities and factors influential to nurse staffing decision-making
}

\author{
Judith Young ${ }^{1}$, Mikyoung Lee ${ }^{* 1}$, Laura Prouty Sands ${ }^{2}$, Sara McComb ${ }^{3}$ \\ ${ }^{1}$ Department of Community and Health Systems, School of Nursing, Indiana University, Indianapolis, Indiana, United States \\ ${ }^{2}$ Department of Human Development, College of Liberal Arts and Human Sciences, Virginia Tech Center for Gerontology, \\ Blacksburg, Virginia, United States \\ ${ }^{3}$ School of Industrial Engineering, Purdue University, West Lafayette, Indiana, United States
}

Received: April 10, 2015

DOI: $10.5430 /$ jha.v4n 4 p24
Accepted: April 24, $2015 \quad$ Online Published: May 7, 2015

URL: http://dx.doi.org/10.5430/jha.v4n4p24

\begin{abstract}
Objective: There is limited published research supporting the effectiveness of nursing workload measurement to comprehensively measure nursing workload and to formulate nurse resource need. Predictive accuracy is impaired due to variation in direct and indirect care-related activities across measurement instruments. This study aimed to (1) identify common nursing activities considered by nurse managers for staffing decision-making, (2) systematically review such nursing activities in relation to existing nursing workload instruments and Nursing Intervention Classification taxonomy, and (3) describe challenges perceived by managers in staffing decision-making.

Methods: A survey was developed from an inclusive review of 20 nursing workload instruments collectively measuring 502 nursing activities. Nurse managers in 13 medical-surgical and two intensive care units at a Midwest healthcare organization identified nursing activities considered daily for staffing decision-making.

Results: Twenty-one activities were commonly considered by at least 90 percent of managers $(n=13)$ for daily staffing decisionmaking, although none of the instruments reviewed included all 21 activities.

Conclusions: Lack of a standardized framework for nursing workload measurement might have led to nurse managers' different perceptions about appropriate determinants of these measurements. A standardized approach for measuring nursing workload would facilitate benchmarking for estimating nurse resource need. Further research is needed to design a systematic infrastructure that ensures staffing to meet patient care need. A process is also needed to alleviate the challenges in staffing decision-making that nurse managers face, such as fluctuations in census and patient acuity, nurse competency-based patient assignments, and limited information resources for staffing estimation.
\end{abstract}

Key Words: Nursing workload, Staffing, Decision-making, Nursing intervention classification

\section{INTRODUCTION}

Nurse staffing is a priority issue for nurse managers to ensure patient safety, nurse satisfaction, and productivity. Research is mounting that supports a significant association between nurse staffing and patient outcomes. ${ }^{[1-4]}$ Increasing the num- ber of registered nurses (RNs) is likely the best strategy to facilitate high care quality; however, with escalating healthcare costs, nurses have been the target of cost-cutting strategies. ${ }^{[5]}$ Therefore, having optimal nurse staffing is highly challenging.

*Correspondence: Mikyoung Lee; Email: leemi@iu.edu; Address: 1111 Middle Drive, Indianapolis, Indiana, United States. 
A variety of nursing workload measurement (NWM) instruments have been developed, refined, and utilized to guide staffing decision-making. The existing NWM instruments can be grossly categorized into three approaches: patient classification system (PCS); nursing workload (NW); and nursing intensity (NI). The PCS, known as the prototype approach, involves a subjective assessment for determining the patient care category most representative of the patient care needs based upon the average timeframes and skill mix required. ${ }^{[6,7]}$ The NW is the summative task approach, using a comprehensive list of tasks or care indicators with numerical sums of average time for and frequency of performing each task determining nursing skills required and resource needs for the next shift or day. ${ }^{[8]}$ The NI approach links direct and indirect care activities performed to specific time standards, healthcare provider educational preparedness, experience and skill level, and patient acuity categories. The sum of time requirements according to skill mix provides estimations for resource need. ${ }^{\left[{ }^{[8}, 9\right]}$

The estimations of nurse staffing needs vary significantly by setting and even across units within a setting, depending upon the types/approaches of NWM instruments used. The predictive accuracy of staffing estimations has often been cited as a challenge due to the limited use of objective tools to estimate staffing and the tools' limited comprehensiveness in fully reflecting the nursing workload required for addressing patient care needs. Multiple factors, including physical, emotional, and cognitive patient care needs, drive nursing activities and impact nursing workload. ${ }^{[10]}$ Therefore, it is very important to gather and comprehensively review nursing activities that have been included in existing NWM instruments with nurse managers in order to find strategies that comprehensively reflect nursing work as well as more accurately predict nurse staffing needs.

This study aimed to (1) identify common nursing activities considered by nurse managers for staffing decision-making in one large health organization, (2) systematically review such nursing activities in relation to existing NWM tools and the Nursing Intervention Classification (NIC), and (3) describe challenges perceived by managers in staffing decisionmaking.

\section{MeTHODS}

\subsection{Survey development}

Twenty workload instruments were reviewed, including three patient classification, ten nursing workload, and seven nursing intensity instruments, and were reflected within the survey to achieve a comprehensive representation of nursing workload (see Table 1). Seventeen of the instruments had been used in an acute care setting, ${ }^{[5,9,11-25]}$ followed by one

Published by Sciedu Press used in a psychiatric setting ${ }^{[26]}$ and two in outpatient settings. ${ }^{[27,28]}$ Few instruments in the studies had been designed based on a theoretical framework; three (15\%) of the 20 instruments were based upon, respectively, Benner's NoviceExpert, the NIC, and Nursing Outcome Classification; ${ }^{[12]}$ Horta's Basic Needs Theory; ${ }^{[13]}$ and the Nursing Process Model. ${ }^{[26]}$

In total, 1,438 nursing activities from 20 instruments were extracted and sorted according to the NIC. The NIC is a comprehensive standardized classification of nursing care interventions that addresses physiological to psychosocial patient care need, illness treatment, and health prevention and promotion in comprehensive dimensions. ${ }^{[29]}$ The NIC includes nursing care provided within and across healthcare settings as well as interventions conducted by nursing care providers at different levels. In addition to direct nursing care, it includes indirect nursing activities such as chart documentation, interdisciplinary collaboration, and communication needs to incorporate within staffing calculations. ${ }^{[29]}$ It is useful for clinical documentation, communication about care across settings, integration of data across systems and settings, competency evaluation, and productivity measurement. ${ }^{[29]}$

The NIC has a taxonomy structure in four levels; at the top level, there are seven domains including Physiological Basic, Physiological Complex, Behavioral, Safety, Family, Health System, and Community. At the $2^{\text {nd }}$ level, 30 classes are specified across the domains, for example, Crisis Management and Risk Management under the domain of Safety. At the $3^{\text {rd }}$ level, there are 542 nursing interventions; each nursing intervention lists a set of specific nursing activities, which constitute the $4^{\text {th }}$ level. Briefly, 1,438 nursing activities are grouped to 542 interventions in 30 classes within seven domains in the $5^{\text {th }}$ edition of NIC. An intervention is defined as any treatment based upon clinical judgment and knowledge that a nurse performs to enhance patient/client outcomes. ${ }^{[29]}$ In the NIC, each intervention is composed of a label, a definition, and a set of activities that a nurse performs to carry out the intervention.

Referring to the definitions of and nursing activities related to each nursing intervention in the NIC, the 1,438 nursing activities were mapped and sorted. Utilizing a second reviewer, duplicated or redundant activities were excluded. As a result, 502 nursing activities were incorporated into the survey along with a frequency rating scale (daily, occasionally, or not at all) to identify nursing activities that nurse managers predominantly consider to determine nurse staffing needs. The greatest number of nursing activities $(n=179)$ was related to 65 interventions and linked to the eight classes 
of the NIC domain Physiologic Complex, which include Electrolyte and Acid-Base Management, Drug Management, Neurologic Management, Perioperative Care, Respiratory Management, Skin/Wound Management, Thermoregulation, and Tissue Perfusion Management. The next greatest number of nursing activities was related to the NIC domain Health Systems, including 103 nursing activities linked to 23 interventions in three classes including Health System Mediation, Health System Management, and Information Management. A third NIC domain, Physiologic Basic, included six classes: Activity \& Exercise Management, Elimination Management, Immobility Management, Nutrition Support, Physical Comfort Promotion, and Self-Care Facilitation. Mapped to these six classes were 101 nursing activities that were part of 41 interventions. Under the fourth NIC domain, Safety, 47 nursing activities were linked to 18 interventions in two classes, Crisis Management and Risk Management. The fifth NIC domain was Behavioral Care, and 47 nursing activities were linked to 26 interventions related to its six classes: Behavior Therapy, Cognitive Therapy, Communication Enhancement, Coping Assistance, Patient Education, and Psychological Comfort Promotion. The sixth NIC domain was Family Care, and 25 nursing activities were matched with 18 interventions under three classes: Childbearing Care, Childrearing Care, and Lifespan Care.

The survey was comprised of: (1) seven questions about unit characteristics related to nursing staffing, (2) questions asking which of 502 nursing activities the respondents routinely used to estimate nurse staffing need, and (3) 13 openended questions regarding challenges related to the staffing decision-making process. Unit characteristics included unit type, census, bed capacity, average nursing hours per patient day, skill mix (the proportion of RN to non-RN staff for each shift), average length of stay, and the frequency of nursing staffing decision-making.

Table 1. Nursing workload measurement instruments included within survey development

\begin{tabular}{|c|c|c|}
\hline & Authors & Names of Instruments (codes) \\
\hline 1 & Crouch \& Williams, $2006^{[11]}$ & Jones Dependency Tool (PCS - 1) \\
\hline 2 & Malloch et al., $1999^{[12]}$ & Third-generation PCS (3PCS) (PCS - 2) \\
\hline 3 & Perroca \& Ek, 2007 ${ }^{[13]}$ & Perroca (PCS - 3) \\
\hline 4 & Davidhizar et al., $1998^{[26]}$ & Psychiatric PCS (NW - 1) \\
\hline 5 & Kwok et al., $2005^{[14]}$ & Simplified Therapeutic Intervention Scoring System (TISS-28) (NW - 2) \\
\hline 6 & Miranda et al., $1997^{[15]}$ & Nine Equivalents of Nursing Manpower Use Score (NEMS) (NW - 3) \\
\hline 7 & Miranda et al., 2003 ${ }^{[16]}$ & Nursing Activities Score (NAS) (NW - 4) \\
\hline 8 & Mullinax \& Lawley, $2002^{[5]}$ & Neonatal Acuity Score (NW - 5) \\
\hline 9 & Pyykko et al., $2004^{[17]}$ & Intensive Care Nursing Scoring System (ICNSS) (NW - 6) \\
\hline 10 & Sawatzky-Dickson \& Bodnaryk, 2009 ${ }^{[18]}$ & Winnipeg Assessment of Neonatal Nursing Needs Tool (WANNNT) (NW - 7) \\
\hline 11 & Scribante et al., $1996^{[19]}$ & Critscore (NW - 8) \\
\hline 12 & Walthier et al., 2004 ${ }^{[20]}$ & Modified Nursing Care Recording System (NCR11) (NW - 9) \\
\hline 13 & Yamase, 2003 ${ }^{[21]}$ & Comprehensive Nursing Intervention Score (CNIS) (NW - 10) \\
\hline 14 & De Jong et al., $2009^{[9]}$ & Not Available (NI - 1) \\
\hline 15 & Duclos-Miller, $19966^{[22]}$ & Labor, Delivery, Recovery, Postpartum Model (LDRP) (NI - 2) \\
\hline 16 & Hlusko \& Nichols, $1996^{[23]}$ & Not Available (NI - 3) \\
\hline 17 & Hoi et al., $2010^{[24]}$ & Workload Intensity Measurement System (WIMS) (NI - 4) \\
\hline 18 & Karr \& Fisher, $1997^{[27]}$ & Not Available (NI - 5) \\
\hline 19 & Moore \& Hastings, $2006^{[28]}$ & Not Available (NI - 6) \\
\hline 20 & Chou et al., 2007 $7^{[25]}$ & Chinese Nursing Interventions in ICU (CNI-ICU) (NI - 7) \\
\hline
\end{tabular}

\subsection{Survey procedure}

The study was approved by the Institutional Review Boards of the healthcare organization and two universities. Nurse managers were informed about the study at an all-campus management meeting. The survey was sent via SurveyMonkey to 32 managers at one large Midwest healthcare system over a three-week period. Any identifiable information was protected by encrypting the information in the data site. Fif- teen of the managers completed the survey, for a response rate of $47 \%$.

\subsection{Data analyses}

Descriptive analyses were conducted to identify common nursing activities considered by nurse managers across units for estimating nurse staffing. The narrative responses to the questions about perceived challenges to staffing decision- 
making were characterized by the following themes: resource availability, nurse competency consideration, nurse satisfaction, and patient outcomes.

\section{Results}

\subsection{Unit characteristics}

Fifteen managers representing medical-surgical units (MSU, $\mathrm{n}=13$ ) and intensive care units (ICU, $\mathrm{n}=2$ ) completed the survey. The average unit occupancy was 77 percent (ranging from $43 \%-90 \%$ ). Length of patient stay ranged from two days in ICUs to 10 days in MSUs. The average nursing hours per patient day (NHPPD) ranged from 23.5 hours for patients in ICUs to 3.2 hours for the medical-surgical patient population. Nurse-to-patient ratios ranged from 1:1 (ICU) to 1:7 (MSU night shift).

\subsection{Nursing activities to estimate nurse staffing needs}

In total, 502 nursing activities were mapped to 200 nursing interventions under 26 classes and six domains of NIC. The number of nursing activities for each domain ranged from 25 (Family) to 189 (Physiologic Complex). Out of 502 nursing activities only 21 (4\%) were commonly considered by at least $90 \%(n=13)$ of the nurse managers for daily staffing decision-making (see Table 2). Although more than one nursing activity comprised each of the NIC nursing interventions, only one nursing activity per intervention was commonly considered when nurse managers estimated nurse staffing. For example, although two nursing activities comprised Nausea Management of NIC, only one of them, "Symptom management of nausea", was commonly considered by nurse managers when estimating nurse staffing. As another example, 57 nursing activities comprised the NIC intervention, "Medication Administration: Intravenous (IV)"; however, "Monitoring IV medication" was the only nursing activity considered by at least than $90 \%$ of nurse managers when estimating staffing needs (see Table 2). In addition to direct nursing activities, at least $90 \%$ of nursing managers considered four indirect care activities that were contained within one NIC class, Information Management (see Table 2). Thirteen of the 502 nursing activities were not considered at all for staffing decision-making by $90 \%$ of nurse managers (see Table 3). ICU managers reported they have also considered some nursing activities that were not listed in the survey, including heavy lifting, adoption, loss of an infant bereavement, and application of an epidural patch. MSU nurse managers reported involvement of child protection service and suspected drug or child abuse were additional nursing activities considered with staffing.

Published by Sciedu Press

\subsection{Challenges in the nurse staffing decision-making process}

\subsubsection{Resource availability}

Staffing calculations were completed at four-, eight-, or twelve-hour intervals or as needed. In two thirds of the units (67\%), including the two ICUs and eight MSUs, staffing needs were calculated every four hours or more frequently as needed due to fluctuation in census, the dynamic nature of nursing workload, and patient acuities. The remaining managers $(n=5)$ reviewed staffing needs shift by shift.

The use of existing NWM instruments was limited. The managers of two MSUs utilized an in-house PCS tool, categorizing patient care needs according to levels one through three. The remainder (86\%), comprised of two ICUs and 11 MSUs, followed a census-driven staffing policy that included a unit staffing grid with predetermined nurse-to-patient ratios and staffing mix. For example, the ICUs had different nurse-to-patient ratios for different types of patients: 2:1 for a patient donor of organs at end of life; 1:1 for a patient within 6 - 8 hours of the postoperative period; and 1:2 for patients of lower acuity, but still meeting critical care criteria requiring frequent monitoring of vital signs and assessment (e.g., every two hours). The nurse-to-patient ratios on the MSUs were reported as 1:5 on the day and evening shifts and $1: 6$ or $1: 7$ on the night shifts.

Seven managers stated that no feature of the electronic health record (EHR) could automatically or directly facilitate staffing decision-making. However, the managers indicated that staffing needs and nurse-to-patient assignments were made by reviewing patient acuity status, which was determined from particular patient information in the EHR (e.g., isolation, history, physical data, medications, fall risk, and social/family issues).

\subsubsection{Nurse competency consideration}

The two ICU nurse managers and eight MSU nurse managers considered nurse competency level for staffing. In particular, nurse competency level was considered when assigning floating nurses from a resource pool. In this case, the charge nurse would verify nurse competency level prior to completing the patient assignments. Specifically, ICU managers considered nurses' competency levels regarding procedures scheduled at the bedside or outside the unit. For example, a nurse not certified in advanced cardiovascular life support would not be assigned to a patient who would be travelling during the shift. Managers of MSUs generally scheduled an appropriate mix of experienced and novice nurses for each shift, and one MSU manager mentioned that a newly graduated nurse would have fewer patients than experienced nurses. Overall, the managers tried to equalize nursing workload within indi- 
vidual nursing assignments by avoiding disproportionately assigning patients with greater care needs to the same nurse.

\subsubsection{Nurse satisfaction}

One ICU manager stated that nurses were probably satisfied with the current staffing processes, NHPPD, and nurse-topatient ratios because she made an effort to ensure that assignments were fair and equitable with the workload evenly dispersed. However, she was concerned that staff morale might be low and nurses might feel frustrated because of physician demands, patient care needs, and the fluctuating census. One MSU nurse manager reported that staff believed the unit was understaffed and nurse satisfaction was lower due to the lack of nursing assistant support, which led to nurses feeling overwhelmed occasionally or on a daily basis. One manager reported, "We staff for patients in the unit only, not for what if situations." Similarly, most managers reported that they were guided by the pre-determined staffing grid and patient census only.

Table 2. Nursing activities considered daily by at least $90 \%$ of managers

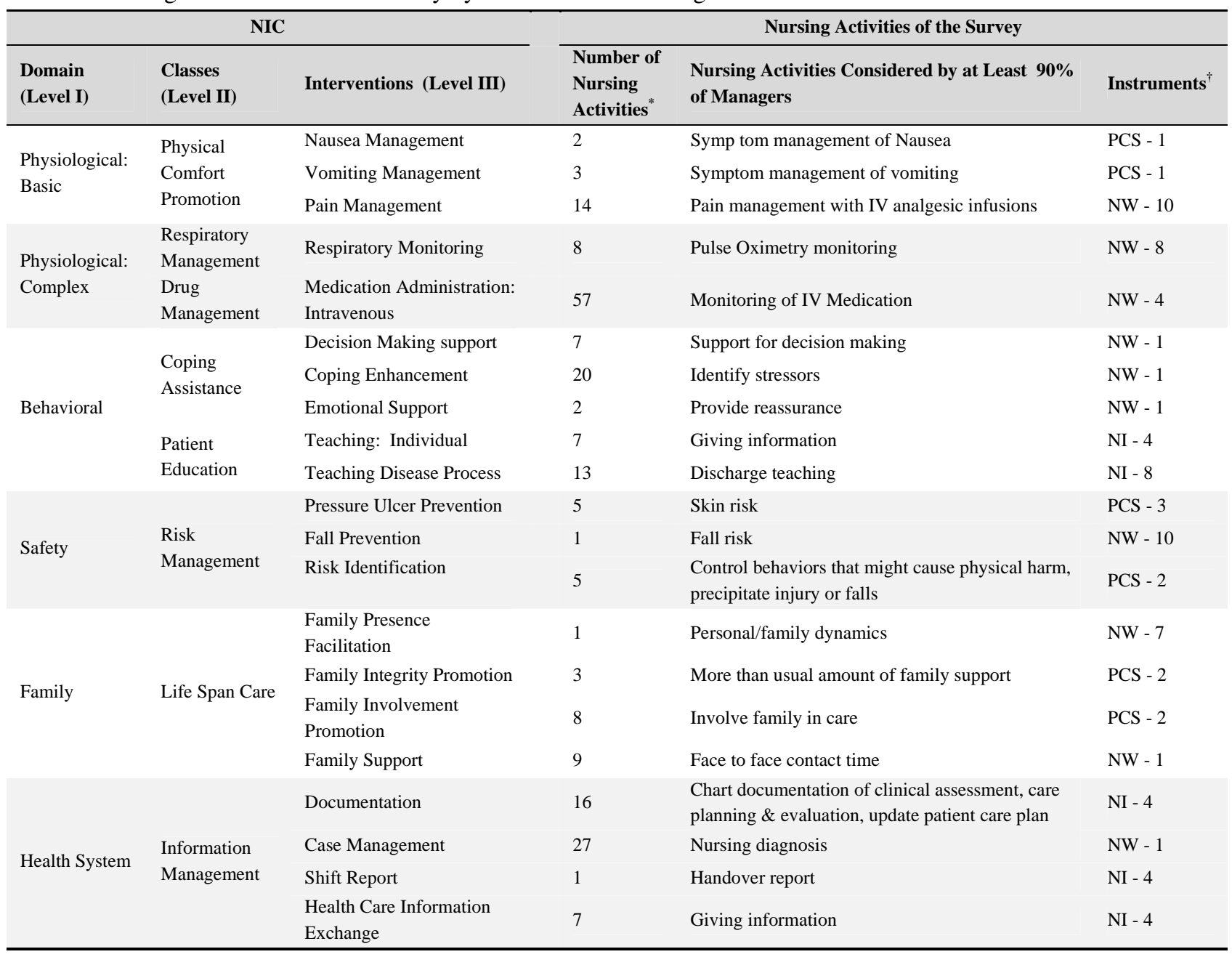

${ }^{*}=$ the number of nursing activities associated with each NIC intervention; ${ }^{\dagger}=$ types of instruments from which the nursing activity was extracted

\subsubsection{Patient outcomes}

One of the ICU managers stated, "Patient teaching is affected if a nurse cannot remain in the room more than 10 to 15 minutes." Both ICU managers remarked that, although the care in their units was of good quality, some care such as education couldn't be done as needed due to time constraints. The MSU managers reported that patient outcomes might be impacted due to heavy workload and high patient-to-nurse ratios, which resulted in insufficient time to provide patient discharge education or social interaction as needed. Some of the MSU managers also expressed their concern that delays in the discharge process could occur due to heavy workload, although it had not happened often, which might impact patient satisfaction. 
Table 3. Nursing activities not considered daily by at least $90 \%$ of managers

\begin{tabular}{|c|c|c|c|c|c|}
\hline \multicolumn{3}{|c|}{ NIC } & \multicolumn{3}{|c|}{ Nursing Activities of the Survey } \\
\hline $\begin{array}{l}\text { Domain } \\
\text { (Level I) }\end{array}$ & $\begin{array}{l}\text { Classes } \\
\text { (Level II) }\end{array}$ & Interventions (Level III) & $\begin{array}{l}\text { Number of } \\
\text { Nursing } \\
\text { Activities }\end{array}$ & $\begin{array}{l}\text { Nursing Activities Not Considered by at Least } \\
\mathbf{9 0 \%} \text { of Managers }\end{array}$ & Instruments $^{\dagger}$ \\
\hline \multirow{6}{*}{$\begin{array}{l}\text { Physiological: } \\
\text { Complex }\end{array}$} & $\begin{array}{l}\text { Neurologic } \\
\text { Management }\end{array}$ & $\begin{array}{l}\text { Tube Care: Ventriculoscopy/ } \\
\text { Lumbar drain }\end{array}$ & 1 & $\begin{array}{l}\text { External ventricular drain requiring frequent } \\
\text { adjustments }\end{array}$ & NW - 7 \\
\hline & $\begin{array}{l}\text { Drug } \\
\text { Management }\end{array}$ & $\begin{array}{l}\text { Medication Administration; } \\
\text { Intravenous }\end{array}$ & 57 & Cassette Change & NI - 6 \\
\hline & $\begin{array}{l}\text { Respiratory } \\
\text { Management }\end{array}$ & $\begin{array}{l}\text { Mechanical Ventilation } \\
\text { Management: Invasive }\end{array}$ & 13 & Jet Ventilation & NW - 5 \\
\hline & Tissue & Circulatory Care: Mechanical & 4 & Mechanically assisted circulation & NW - 10 \\
\hline & Perfusion & Assist Device & 4 & Intra-aortic balloon assist & NI - 8 \\
\hline & Management & Shock Management: Cardiac & 6 & Post-operative cardiac surgery for the first 24 hours & NW - 8; NW - 3 \\
\hline \multirow{3}{*}{ Behavioral } & \multirow{3}{*}{$\begin{array}{l}\text { Patient } \\
\text { Education }\end{array}$} & \multirow{3}{*}{ Teaching Procedure/treatment } & 11 & Teaching endometrial biopsy & NI - 6 \\
\hline & & & 11 & Colposcopy & NI - 6 \\
\hline & & & 11 & IUD insertion & NI - 6 \\
\hline \multirow{4}{*}{$\begin{array}{l}\text { Health } \\
\text { Systems }\end{array}$} & \multirow{4}{*}{$\begin{array}{l}\text { Health } \\
\text { System } \\
\text { Management }\end{array}$} & \multirow{3}{*}{ Examination Assistance } & 43 & Insert intra cerebral pressure device & NW - 10 \\
\hline & & & 43 & Cystography & NW - 10 \\
\hline & & & 43 & PAP test routine Gynecological test & NI - 6 \\
\hline & & Supply Management & 14 & Management of a burn bed & NW - 10 \\
\hline
\end{tabular}

* = the number of possible nursing activities associated with each NIC intervention; ${ }^{\dagger}=$ the types of instruments from which the nursing activity was extracted

\section{Discussion}

This study confirmed that staffing decision-making represented a central activity for nursing managers since the majority reviewed and adjusted staffing every four hours or more frequently as needed. Measuring nursing workload is an international concern of healthcare providers and a variety of NWM instruments has been available to guide staffing decision-making. This study initially reviewed 20 NWM instruments that had presented the contents of the instruments in published articles, although there could be more diverse NWM instruments in existence. The fact that 502 unique nursing activities were identified from a total of 1,438 nursing activities extracted from these 20 instruments suggests that nursing workload has been very differently measured by different instruments. Furthermore, the extent to which nursing work is comprehensively measured by each of the instruments is in question, and comparing their nursing workload effects on patient or system outcomes would be difficult due to the great differences in the workload measurements.

Surprisingly, out of the 502 nursing activities only 21 were reported to be commonly considered by at least $90 \%$ of the participating nurse managers for daily staffing decisionmaking; 17 direct nursing activities and four indirect care activities were included in this set of 21 activities. When the cut-off for common consideration was set at $80 \%, 34$ nursing activities were identified, and the number of nursing activities commonly considered by more than $50 \%$ of managers increased to 50. Notably, the great majority of the 502 nursing activities within the survey were not commonly considered. These findings suggest that different determinants of nursing workload across units are relevant to the dominant patient populations in each unit. Furthermore, the findings also illustrate that there were diverse nursing workload measurements used across units, resulting in limited benchmarking and limited evidence to support staffing needs. The lack of a standardized framework for NWM, even within this one organization, might have led nurse managers to different opinions about appropriate determinants of nursing workload measurements.

No one instrument contained all of the 21 nursing activities identified by at least $90 \%$ of nurse managers. This finding may explain why there have been doubts about the reliability of workload measurement approaches in their present form and why the available NWM tools remain underutilized. At this study site only two managers used a PCS tool; the majority of managers used a census-driven staffing policy, which included a unit staffing grid with predetermined nurseto-patient ratios and staffing mix. This static approach is limited for addressing fluctuations in census, the dynamic nature of nursing workload, and patient acuities. Inconsistent dimensions and the lack of a standardized approach for measuring nurse workload compound the challenges for managers to account for multiple factors that influence workload complexity ${ }^{[6]}$ Accuracy for determining nursing resource need is essential to support high quality nursing care and patient safety in a cost-effective manner. We believe that the use of an instrument whose framework is scientific, comprehensive, and holistic is an immediate need to standardize the 
approach for measuring nursing workload.

In the 502 nursing activities extracted in our review, the NIC was used as the framework to organize the similarities and differences in aspects of the nursing activities. The NIC provides consistent dimensions as represented in its taxonomy, and it provides a standardized approach for measuring nursing workload with time estimates and type of personnel to perform each of the 542 nursing interventions. ${ }^{[29]}$ For example, Nausea Management is appropriate for RNs with basic education to perform and requires 16 - 30 minutes. Pain Management also needs to be provided by RNs with basic education but takes more than one hour to perform. The NIC also lists the interventions appropriate for delegation to a nursing assistant or to an $\mathrm{RN}$ with post-basic education. It was good to find that most of the managers in this study considered nurse competency level and patient acuity with assignment decisions. In the future, it would be meaningful to review the nurse managers' complex nursing staffing decision process, including nurse-to-patient assignment ratios, delegation, nurse competency judgements according to the nursing workload measures, along with the set of time estimates and type of personnel determined by the NIC.

Although nurses were reported to be satisfied with the current staffing processes, the managers were concerned that staff nurses had low morale and frustration due to the fluctuating census and lack of nursing assistant support to meet care needs on a daily basis. A system or resource to address these problems is needed for nurse managers. In the survey, nurse managers indicated that no feature of the EHR could automatically or directly facilitate staffing decision-making, and they utilized the EHR to a minimal extent. Using available information technology to facilitate prompt and accurate estimations for nurse resource needs would provide a more efficient approach. Standardized terminologies such as those used by the NIC could be built into such healthcare technology.

\section{Limitations}

The survey was administered in one healthcare setting, and therefore the representativeness of the study findings might be limited; however, the survey did embrace the diverse units within the setting. Furthermore, only half of the nurse managers actually completed the survey, and feedback suggested this was at least partly because it was lengthy and required up to two hours for completion. This may have affected the quantity and quality of the data. Finally, the survey instrument may not have included all factors related to nursing staffing decision-making; however, the study provided a good opportunity to review the capacities of existing NWM instruments as well as the reality of the workload measurement process with nurse managers.

\section{Conclusions}

There has been no comprehensive and systematic approach to measure nurse workload. Varied dimensions, the lack of a standardized approach for measuring nursing workload, and the opportunity for subjectivity in judgments have compounded the challenge for managers to accurately estimate nurse resource predictions. A standardized approach for measuring nursing workload would address an immediate need to assist nurse staffing decision-making. The NIC System could provide a framework for the development of a standardized approach to determine nurse workload; its taxonomy would organize the nursing workload measurements in a comprehensive approach, and the labels of nursing interventions and activities would help to represent and measure nursing work in a standardized manner. The review of existing NWM tools or the development of a tool with the NIC is recommended to determine comprehensive nursing workload measures appropriate for particular types of units or patient populations. Although the NWM tools would be specific to the dominant patient populations of each unit, the tools based on the NIC would facilitate benchmarking of staffing impacts across settings or patient populations because standardized terms are used. The NWM tool integrated with hospital information systems is highly recommended to assist nurse administrators to efficiently optimize nurse staffing as well as to ensure patient safety, quality care, and nurse satisfaction.

\section{CONFlicts OF INTEREST Disclosure}

The authors declare no conflict of interest.

\section{REFERENCES}

[1] Aiken L, Clark S, Sloane D. Hospital nurse staffing and patient mortality, nurse burnout, and job dissatisfaction. Journal of the American Medical Association. 2002; 288(16): 1987-1993. PMid: 12387650. http://dx.doi.org/10.1001/jama.288.16.1987

[2] Aiken L, Clarke S, Silber J, et al. Hospital nurse staffing, education, and patient mortality. LDI Issue Brief. 2003; 9(2): 1-4. PMid:
14621688.

[3] Kane R, Shamliyan T, Mueller C, et al. The association of registered nurse staffing levels and patient outcomes: Systematic review and meta-analysis. Medical Care. 2007; 45(12): 1195-1204. PMid: 18007170. http://dx.doi.org/10.1097/MLR.0b013e3 $181468 \mathrm{ca} 3$

[4] Needleman J, Buerhaus P, Mattke S, et al. Nurse-staffing levels and 
the quality of care in hospitals. New England Journal of Medicine. 2002; 346(22): 1715-1722. PMid: 12037152. http://dx.doi.org /10.1056/NEJMsa012247

[5] Mullinax C, Lawley M. Assigning patients to nurses in neonatal intensive care. Journal of the Operational Research Society. 2002; 53: 2535. http://dx.doi.org/10.1057/palgrave/jors/2601265

[6] De Groot H. Patient classification system evaluation part 1: Essential system elements. Journal of Nursing Administration. 1989a; 19(6): 30-35. PMid: 2723792. http://dx.doi.org/10.1097/0000511 0-198906010-00010

[7] De Groot H. Patient classification system evaluation part 2: System selection and evaluation. Journal Nursing Administration. 1989b; 19(7): 24-30. PMid: 2760676

[8] Brady A, Byrne G, Horan P, et al. Measuring the workload of community nurses in Ireland: A review of the workload measurement systems. Journal of Nursing Management. 2007; 15: 481-489. PMid: 17576246. http://dx.doi.org/10.1111/j.1365-2834. 2007.00663.x

[9] De Jong A, Leeman J, Middelkoop E. Development of a nursing workload measurement instrument in burn care. Burns-Oxford. 2009; 35: 942-948. PMid: 19577371. http://dx.doi.org/10.1016/j .burns. 2009.04.005

[10] Carayon P, Alvarado C. Workload and patient safety among critical care nurses. Critical Care Nursing Clinics of North America. 2007; 19: 121-129. PMid: 17512468. http://dx.doi.org/10.1016/j .ccell.2007.02.001

[11] Crouch R, Williams S. Patient dependency in the emergency department (ED): Reliability and validity of the Jones Dependency Tool. Accident and Emergency Nursing. 2006; 14: 219-229. PMid: 16904323. http://dx.doi.org/10.1016/j. aaen.2006.06.005

[12] Malloch K, Neeld A, McMurry C, et al. Patient classification systems, Part 2: The third generation. The Journal of Nursing Administration. 1999; 29(9): 33-42. PMid: 10491667. http://dx.doi.org/10. 1097/00005110-199909000-00008

[13] Perroca M, Ek A. Assessing patient's care requirements: A comparison of instruments. Scandinavian Journal of Caring Science. 2007; 21: 390-396. PMid: 17727552. http://dx.doi.org/10.1111/j .1471-6712.2007.00484.x

[14] Kwok Y, Wing W. The reliability and validity of the therapeutic activity index. Journal of critical care. 2005; 20(3): 257-263. PMid: 16253795. http://dx.doi.org/10.1016/j.jcrc. 2005 .06 .004

[15] Miranda D, Moreno R, Iapichino G. Nine equivalents of nursing manpower use score (NEMS). Intensive Care Medicine. 1997; 23 : 760-765. http://dx.doi.org/10.1007/s001340050406

[16] Miranda D, Nap R, de Rijk A, et al. Nursing activities score. Critical Care Medicine. 2003; 31(2): 374-382. PMid: 12576939. http: //dx.doi.org/10.1097/01.CCM.0000045567.78801.CC
[17] Pyykko A, Ala-Kokko T, Laurila J, et al. Validation of the new intensive care nursing score system (ICNSS). Intensive Care Medicine 2004; 30: 254-259. PMid:14714105. http://dx.doi .org/10.10 07/s00134-003-2040-4

[18] Sawatzky-Dickson D, Bodnaryk K. Validation of a tool to measure neonatal nursing workload. Journal of Nursing Management. 2009; 17: 84-91. PMid: 19166526. http://dx.doi.org/10.1111/j.1 $365-2834.2008 .00877 . x$

[19] Scribante J, Muller M, Lipman J. Development and validation of a critical care patient classification system. American Journal of Critical Care. 1996; 5(4): 282-288. PMid: 8811151.

[20] Walther S, Jonasson U, Karlsson S, et al. Multicentre study of validity and interrater reliability of the modified Nursing Care Recording System (NCR11) for assessment of workload in the ICU. Acta Anaesthesiologica Scandinavica. 2004; 48: 690-696. PMid: 15196100 http://dx.doi.org/10.1111/j.0001-5172.2004.00397.x

[21] Yamase H. Development of a comprehensive scoring system to measure multifaceted nursing workloads in ICU. Nursing and Health Sciences. 2003; 5: 299-308. http://dx.doi.org/10.1046/j.1 442-2018.2003.00165.x

[22] Duclos-Miller P. Workload measurement tracking system. Nursing Management. 1996; 27(9): 39-41. http://dx.doi.org/10.1097 /00006247-199609000-00017

[23] Hlusko D, Nichols B. Can you depend on your patient classification system? The Journal of Nursing Administration. 1996; 26(4): 39-44 PMid: 8774471. http://dx.doi.org/10.1097/00005110-199 604000-00012

[24] Hoi S, Ismail N, Ong L, et al. Determining nurse staffing needs: The workload intensity measurement system. Journal of Nursing Management. 2010; 18: 44-53. http://dx.doi.org/10.1111/j.136 5-2834.2009.01045.x

[25] Chou S, Wu L, Chang I, et al. The Chinese nursing interventions instrument. Journal of Nursing Scholarship. 2007; 39(2): 198-199. PMid: 17535322. http://dx.doi.org/10.1111/j.1547-5069. 2007.00167.x

[26] Davidhizar R, Mallow G, Bechtel G, et al. A patient classification system for the chronic psychiatric patient. Australian and New Zealand Journal of Mental Health Nursing. 1998; 7: 126-133. PMid: 10095462.

[27] Karr J, Fisher RA. Patient classification system for ambulatory care. Nursing Management. 1997; 28(7): 27-28. PMid: 9335835.

[28] Moore M, Hastings C. The evolution of an ambulatory nursing intensity system. The Journal of Nursing Administration. 2006; 36(5): 241-248. PMid: 16705305. http://dx.doi.org/10.1097/000 05110-200605000-00017

[29] Bulechek G, Butcher H, Dochterman J. Nursing Interventions Classification (NIC). (5 ${ }^{\text {th }}$ ed.) St Louis, MO: Mosby Elsevier; 2008. 